\title{
Effects of temperature variability on community structure in a natural microbial food web
}

\author{
AXEL ZANDER, LOUIS-FÉLIX BERSIER ${ }^{\dagger}$ and SARAH M. GRAY ${ }^{\dagger}$ \\ Department of Biology - Ecology and Evolution, University of Fribourg, Chemin du Musée 10, Fribourg CH-1700, Switzerland
}

\begin{abstract}
Climate change research has demonstrated that changing temperatures will have an effect on community-level dynamics by altering species survival rates, shifting species distributions, and ultimately, creating mismatches in community interactions. However, most of this work has focused on increasing temperature, and still little is known about how the variation in temperature extremes will affect community dynamics. We used the model aquatic community held within the leaves of the carnivorous plant, Sarracenia purpurea, to test how food web dynamics will be affected by high temperature variation. We tested the community response of the first (bacterial density), second (protist diversity and composition), and third trophic level (predator mortality), and measured community respiration. We collected early and late successional stage inquiline communities from S. purpurea from two North American and two European sites with similar average July temperature. We then created a common garden experiment in which replicates of these communities underwent either high or normal daily temperature variation, with the average temperature equal among treatments. We found an impact of temperature variation on the first two, but not on the third trophic level. For bacteria in the high-variation treatment, density experienced an initial boost in growth but then decreased quickly through time. For protists in the high-variation treatment, alpha-diversity decreased faster than in the normal-variation treatment, beta-diversity increased only in the European sites, and protist community composition tended to diverge more in the late successional stage. The mortality of the predatory mosquito larvae was unaffected by temperature variation. Community respiration was lower in the high-variation treatment, indicating a lower ecosystem functioning. Our results highlight clear impacts of temperature variation. A more mechanistic understanding of the effects that temperature, and especially temperature variation, will have on community dynamics is still greatly needed.
\end{abstract}

Keywords: bacterial density, food web structure, microcosm, protist community, Sarracenia purpurea, successional stage, temperature variation

\section{Introduction}

Increased mean temperatures due to climate change are having an effect on community-level dynamics in a majority of ecosystems worldwide (Traill et al., 2010). Research has already demonstrated that species distributions are being shifted (e.g. Walther et al., 2002; Parmesan, 2006), thus impacting community interactions (e.g. Gilman et al., 2010), mutualistic dynamics (e.g. Nakazawa \& Doi, 2012), and the functioning of whole ecosystems (e.g. Yvon-Durocher et al., 2012). In tropical ecosystems, this increase in temperature is thought to be especially problematic because tropical species already live near their upper thermal limits (Laurance et al., 2011; Nguyen et al., 2011). In temperate and boreal regions, a $1-4{ }^{\circ} \mathrm{C}$ increase in temperature is, in regard to performance, possibly more beneficial than detrimental for the existing species (Tuck \& Romanuk,

Correspondence: Axel Zander, tel. +4126 300 8856, fax +4126 300 9698, e-mail: axel.zander@unifr.ch

'Senior Authorship.
2012; Vasseur et al., 2014) because ecosystem processes can be accelerated (Maracchi et al., 2005; Lindner et al., 2010). However, recent climate models have also predicted that climate change will not only involve an increase in mean temperature, but also an increase in temperature variation and a higher probability of extreme events (e.g. drought and extreme maximum and minimum temperatures; IPCC 2013). With this increased temperature variability, species from both temperate and tropical environments are likely to be exposed to conditions beyond their maximum temperature limit (Deutsch et al., 2008). Extreme temperature events may therefore be the most important driving forces for determining climate change-induced community dynamics in many ecological systems (Gutschick \& BassiriRad, 2003). Increased temperature variability could thus have a larger impact on species than an increase in the mean temperature alone (Vasseur et al., 2014).

However, to date, the majority of climate change experiments have increased temperature according to 
IPCC predictions (increase of $2-4{ }^{\circ} \mathrm{C}$, IPCC 2013), while either reducing or keeping the natural temperature variance at the status quo (see Thompson et al., 2013). As a result, the effect of increasing temperature variability on community dynamics remains unclear. It is therefore essential to start to include temperature variation as a treatment in climate change research in order to more fully address the effect that climate change will have on ecosystems. In addition, many studies have been conducted at the population and species level, while information about the impact of climate change on higher organization- levels, such as whole communities or food webs, is lagging behind ( $\mathrm{O}^{\prime}$ Gorman et al., 2014).

Food webs in freshwater enclosed habitats (i.e. shallow lakes and ponds), in particular, may be especially vulnerable to climate change because these habitats are usually more isolated than terrestrial ecosystems, resulting in species having fewer options for dispersal when water temperature exceeds their temperature limit (Woodward \& Hildrew, 2002; Deutsch et al., 2008; Vasseur et al., 2014). Furthermore, with increasing heat and drought levels due to climate change-induced extreme events, the habitable areas (waterbodies) can reduce in size and possibly disappear (Salerno et al., 2014), resulting in the local extinction of species. Despite their apparent vulnerability to climate change, only one of 21 studies mentioned in the review by Thompson et al. (2013) experimentally addressed the implications of extreme events on the communities in these enclosed freshwater systems.

From the experiments that have been published, predictions can be made with regard to the effect of increased mean temperature on community dynamics in enclosed freshwater systems. There will likely be a reduction in trophic levels (Beisner et al., 1997), a shift in body size towards smaller species (e.g. Moore et al., 1996), an increase in bacterial densities (e.g. Elliott et al., 2006), and the abundance and composition of species in different levels in a food web will be disproportionately affected (e.g. Strecker et al., 2004). However, it is more difficult to assess the effect of increased temperature variation on communities because its effect is expected to be nonlinear. In terms of diversity, this nonlinear effect can be compared to the intermediate disturbance hypothesis, in which an intermediate level of temperature variation could provide optimal diversity levels, while a low or high level of this variation could reduce diversity (Burgmer \& Hillebrand, 2011). However, the effect of temperature variation on food web dynamics will also depend on the thermal range of the species, which may be difficult to predict based only on body size or trophic-level position (Stevenson, 1985; Liu et al., 1995; Stewart et al., 2013).
Furthermore, the successional stage of these communities may also be important for buffering the effect of increased temperature variation. It can be hypothesized that communities in an early successional stage are more likely to be resistant against environmental changes than communities in late succession, as they contain a high proportion of pioneer species (del Moral \& Wood, 1993; Foster \& Tilman, 2000) that can prosper under a wide spectrum of environmental conditions (Bazzaz, 1979; Pineda-garcía et al., 2013). These early successional communities also usually harbour more small species compared to later successional stages (e.g. Odum, 1969; del Moral \& Wood, 1993; Foster \& Tilman, 2000). These small species can adapt quickly to environmental changes due to higher metabolic rates and fast generation times (Sommer et al., 1986; Jiang et al., 2011), making them less likely to be affected by environmental change. Late successional communities, on the other hand, are composed of species that have been selected via biotic and abiotic environmental filters (Lortie et al., 2004). The species that successfully pass through these filters are the ones that are able to survive in the current temperature regime of the habitat. These species are usually larger in body size and devote more of their energy to competition (e.g. Sommer et al., 1986; Wootton, 1993; Foster \& Tilman, 2000) than early successional species, which may make them less likely to cope with higher variation in environmental conditions.

To better understand how temperature variation will impact enclosed freshwater food webs, and how the successional stage of a community will influence the results, we conducted an experiment using the Sarracenia purpurea aquatic model system. This food web is typically tri-trophic and is composed of bacteria, protists, and arthropod larvae. In this system, as well as in larger scale enclosed freshwater systems, early successional communities consist of a pool of small-bodied, fast-growing pioneer species which may be physiologically better adapted to rapid temperature changes than the slower-growing, larger-bodied species found in later succession (e.g. Sommer et al., 1986; Gray, 2012; Miller \& terHorst, 2012).

To address the importance of temperature variation on food web dynamics, we increased temperature variation while keeping mean temperatures (thermal sums) constant. We accomplished this by manipulating temperature variance as repeated and alternating extreme hot and cold events. These temperatures were within the observed temperature range measured inside Sarracenia leaves in the field and have thus been already experienced by the aquatic community (Figs S2, S9-S12; Table S7). We then measured the impact that increased temperature variation had on the three trophic levels - 
bacteria, protists, and mosquito larvae - at two different successional stages.

We are aware that climate change-related effects of mean and variance interact (see Bozinovic et al., 2011), but the purpose of this experiment was to determine the magnitude of influence temperature variation could have on food web dynamics. We explored five hypotheses. (i) Extreme temperature variation events will disproportionately increase the density of bottom trophic level organisms. The reasoning is, when temperature increases, due to the small-body size of these species, their metabolic rate will increase faster than those of larger species (Brown et al., 2004), also allowing them to adapt more quickly to environmental changes (Daufresne et al., 2009). We explored this question by measuring bacterial density. (ii) Increased temperature variation will reduce species diversity in the intermediate trophic level to only the species that can tolerate large temperature extremes. This point was addressed by determining changes in the diversity and composition of the protists. (iii) Due to the large body size and slow generation time of species in the top trophic level, increased temperature variation is expected to cause high mortality of predators (Petchey et al., 1999; Vasseur et al., 2014). This was determined by measuring the change in mortality rate of the mosquito larvae. (iv) In the aquatic community of the S. purpurea system and also in larger scale enclosed freshwater systems, we expect the general impact of temperature variation to be stronger in late successional communities compared with early successional communities, as the latter species (fast-growing pioneer species) can adapt more quickly to rapid temperature changes due to faster generation times, than the slower-growing, larger-bodied species found in later succession (e.g. Sommer et al., 1986; Gray, 2012; Miller \& terHorst, 2012). (v) In addition, we hypothesize that community respiration will not be markedly affected by increased temperature variation. Our reasoning is that species will respire more as temperature increases (e.g. Ratkowsky et al., 1983; Lloyd \& Taylor, 1994) towards an optimum; however, these species will also experience temperature extremes where they will respire less. These extreme low and high temperatures will stimulate periods of inactivity, thus reducing respiration and counterbalancing the amount of respiration acquired during periods spent in optimal temperature regimes.

\section{Materials and methods}

\section{Study system}

Usage of bacteria and protist microcosms as model systems for larger, more complex ecosystems is a common practice and helps accelerate studies that would otherwise take much more time (for a good overview see Altermatt et al., 2015). Sarracenia purpurea is a carnivorous pitcher plant whose leaves fill with rainwater after opening into their characteristic pitcher shape during the summer months. These leaves capture insects, which drown in the rainwater. Bacteria form the bottom trophic level of the aquatic community and decompose the drowned insects, providing the nutrients for the higher trophic levels of the aquatic community. Protist species form the intermediate trophic level and consume the bacteria. In the plant's native range of North America, a third trophic level also exists, which is composed of the mosquito larvae Wyeomyia smithii. In Europe, where the plant has been introduced, the food web consists mostly of bacteria and protists and no Culicidae larvae have been observed (Fragnière, 2012; Zander et al., 2016). Nematodes, rotifers, mites, and flesh fly larvae can also inhabit the aquatic community in both the introduced and native range (Adlassnig et al., 2010; Zander et al., 2016), but are rarer in occurrence and numbers of individuals compared to the single cellular organisms (Baiser et al., 2012). The leaves that open during the growing season in year 1 will overwinter and, along with their aquatic community, will be present in year 2 (Heard, 1998). This characteristic makes this model system more physically stable than ephemeral systems (e.g. puddles) and therefore more comparable to larger scale enclosed freshwater systems (e.g. tree holes and rock pools).

Although the inquiline communities in the native and introduced range are quite different in species composition (see Gebühr et al., 2006 and Buckley et al., 2010), the successional stages are similar in pattern (Fragnière, 2012; Gray, 2012; Zander et al., 2016). Shortly after the leaf opens into its pitcher shape, random immigration events lead to the establishment of the first early successional species (ca. 2 weeks). After 4 weeks, most elements of the food web are present (late succession) (Gray, 2012; Miller \& terHorst, 2012). These similarities between the native and introduced range suggest that even with differing species composition, broader ecological rules can be generalizable across the large geographic range of this species. This characteristic of the S. purpurea system makes it feasible to conduct experiments where multiple field sites can be used as replicates. In addition, another advantage of using these inquiline communities is the ability to access and manipulate several successional stages of an entire natural ecosystem during a single field season.

\section{Experimental set-up}

We collected early and late successional communities from four climatically similar sites. Two of these sites were from North America and two sites were from Europe. The site selection allowed us to determine if origin (native and introduced range) would have an effect on the results, even when other climatic features were controlled for across all four sites. Note that inquiline communities of $S$. purpurea in Europe have experienced only a short co-evolutionary history with the plant. We then conducted a common garden experiment using the two successional stages of the Sarracenia pitcher inquiline communities from the four sites. We placed each of these communities into two temperature treatments: normal 
temperature variation and high temperature variation. We followed the changes in bacterial (prey) density, protist (predator) composition and diversity, and mosquito larvae (top predator) mortality through time. Additionally, we measured and compared the respiration of the communities at the end of the experiment, as a proxy for ecosystem functioning. Each treatment was replicated 4 times, resulting in 64 samples (2 temperature variations $\times 2$ successional stages $\times 4$ origins $\times 4$ repetitions).

\section{Field collection}

The four sites used in the experiment were similar in terms of the July mean, maximum, and minimum temperature (temperature averaged across 50 years, Worldclim data, www.worldclim.org, Fig. S1a, b) and day length, due to similar northern latitudes. The two North American sites were from Québec (Lac des Joncs (LacJ), $48^{\circ} 29^{\prime} 61.00^{\prime \prime} \mathrm{N}, 68^{\circ} 77^{\prime} 15.55^{\prime \prime} \mathrm{W}$; Lac Rimouski (LacR), $\left.48^{\circ} 18^{\prime} 32.71^{\prime \prime} \mathrm{N}, 68^{\circ} 28^{\prime} 14.68^{\prime \prime} \mathrm{W}\right)$ and the two European sites were from Switzerland (Les Embreux (LE), $47^{\circ} 15^{\prime} 45.82^{\prime \prime} \mathrm{N}$, $7^{\circ} 6^{\prime} 57.79^{\prime \prime} \mathrm{E}$; Les Tenasses (LT), 46 $29^{\prime} 28.51^{\prime \prime} \mathrm{N}, 6^{\circ} 5^{\prime} 16.04^{\prime \prime} \mathrm{E}$ ). At all four sites, unopened leaves that were about to open into the characteristic pitcher shape were randomly selected and marked at the beginning of July. Two weeks later, another subset of unopened leaves were selected and marked. After one month, the aquatic inquiline communities were collected from all marked leaves. The water collected from leaves that had been marked during the first time period ( 1 month old) was designated as 'late succession' communities and the water collected from leaves marked during the second time period (2 weeks old) was designated as 'early succession' communities. The early and late successional communities used in the experiment were collected simultaneously at all four sites on 30 July 2013, with one person designated to sample at one field site. The same protocol for marking the leaves and the sterile collection and storage of samples was followed by all people involved. Collecting the water from the marked leaves involved mixing the contents inside each leaf by gently pipetting. The water from each leaf was then pooled together under sterile conditions into a common container, with early and late successional communities placed in separate containers.

After field collection, the samples were sieved to remove large insect detritus pieces and invertebrate larvae. The removal of large detritus was performed so that the amount of food available during the experiment was homogenized across replicates and treatments. For the Québec samples, all water was double-checked for the presence of mosquito and other insect larvae, and these larvae were subsequently removed. All samples were then stored in cool conditions until the experiment started (approximately $72 \mathrm{~h}$ after collection). During this time, Swiss samples were transported under the same cold conditions to the University of Québec in Rimouski, where the experiment took place.

\section{Experimental preparation}

On the starting day of the experiment, the bacterial density of all communities (the pooled early and pooled late successional community within each site) was measured by flow cytometry and then standardized by diluting with sterile deionized water. Fresh third-instar Wyeomyia smithii larvae were also collected during this time from $S$. purpurea leaves present at the Lac de Rimouski site in Québec. After bringing the mosquito larvae back to the laboratory, they were placed into autoclaved, deionized water for $30 \mathrm{~min}$. This procedure was repeated 4 times to rid the larvae of contaminating microorganisms as much as possible. Note that while bacterial density was standardized, the protist community composition varied among the four sites and the two successional stages.

\section{Experimental procedure}

Twenty $\mathrm{ml}$ of the homogenized starting culture was then transferred to sterile 50-ml macrocentrifuge tubes. There were in total eight replicate communities per successional stage for every site. All 64 tubes had $2 \mathrm{ml}$ of autoclaved glass beads at the bottom to mimic the insect exoskeletons and detritus naturally found at the bottom of Sarracenia pitchers (Gray et al., 2015) and were wrapped with opaque paper until the $25 \mathrm{ml}$ mark to mimic light conditions present inside Sarracenia leaves. A $1 \mathrm{ml}$ solution of autoclaved fish food (Tetramin, $5.4 \mathrm{~g} \mathrm{l}^{-1}$ ) was added as resources to all microcosms. Fish food was chosen because it is an effective way to provide standardized nutrient levels across all treatments. Also, this food is commonly used in Sarracenia research (e.g. Cochran-Stafira \& von Ende, 1998; terHorst et al., 2010; Kadowaki et al., 2012; Gray et al., 2015; Zander et al., 2016) because it has been shown to provide similar results as to when insects are used as the resource in experiments (e.g. terHorst et al., 2010). Two third-instar larvae of Wyeomyia smithii were then placed in every community, corresponding on average to the observed larval densities in Sarracenia leaves in northern latitudes of the North American range (Nastase et al., 1995; Buckley et al., 2003; Hoekman, 2007). The larvae were checked daily for pupation rate and survival and were immediately replaced if they had died or reached the fifth-instar, nonfeeding stage. The replacement larvae were stored in incubators programmed to the normal temperature variation conditions.

\section{Temperature treatments}

For the communities from each site, we divided the 8 tubes per successional stage into two temperature treatments: 'normal temperature variation' and 'high temperature variation'. The normal temperature variation treatment corresponded to the average daily variability of the four sites in July temperatures (data from worldclim.org, Figs S1a, S2a, c) and varied from 10 to $21{ }^{\circ} \mathrm{C}$ over $24 \mathrm{~h}$. July temperatures were used because this was the month in which the communities were collected from all 4 field sites. The 'high temperature variation' treatment corresponded to daily high-variation events that are experienced within the leaves of S. purpurea by the aquatic community during the month of July (Figs S2a-c, S9-S11; Table S7, incubator temperatures varied from 4 to $35^{\circ} \mathrm{C}$ over $24 \mathrm{~h}$ ). For both treatments, the mean temperature remained constant at $15.4^{\circ} \mathrm{C}$, which is the averaged mean 
temperature of the 4 sites used in the experiment. By holding the mean temperature constant, we were able to test the effect of increased temperature variation on food web dynamics.

Two incubators (Sanyo MIR-154) were programmed either to 'high temperature variation' or 'normal temperature variation'. In both incubators, temperatures changed in a stepwise process every two hours, with the temperature cycle repeating every $24 \mathrm{~h}$ (see Fig. S2c). The experimental tubes were arranged in a randomized block design and placed according to their designated temperature treatment into the incubators. Note that both treatments received the same amount of energy; however, the high-variation treatment received more energy that could be used by metabolism than the normal-variation treatment (concept of growing degree day; e.g. Neuheimer \& Taggart, 2007).

\section{Measured variables}

On days 0 (beginning), 2, 4, and 6 (end) of the experiment, we determined the bacterial densities, protist community composition and diversity, and mosquito mortality. For each community, a flow cytometer was used to determine bacterial density, and an aliquot of $80 \mu \mathrm{l}$ was used to determine the presence/absence of all protist species with a compound microscope (100 and $400 \times$ fold magnification). For identification of protist morphospecies, we used Streble \& Krauter (2002). Mosquito mortality was visually inspected daily. Note that alpha-diversity of the protist can increase with time when very rare species become more abundant. Additionally, on Day 6, respiration of a $1 \mathrm{ml}$ sample of each community was measured using the MicroResp TM system (The James Hutton Institute, Scotland). The protocol used was adapted from the manufacturers (Carmen, 2007) and is described in detail in Zander et al. (2016). For data presentation, the lowest measured value of respiration was set to 0 and all others were changed accordingly.

\section{Statistical analyses}

The effect of temperature variability through time on the bacterial density, presence or absence of protist morphospecies (measured by alpha- and beta-diversity), mosquito mortality, and respiration were evaluated with linear mixed-effect models (lme). The explanatory fixed factors were the variability of the temperature, the successional stage, and the community origin status. The random factor was time since the start of the experiment (days 2, 4, and 6). Temporal beta-diversity was measured for each protist community as the average Jaccard distance between sampling days 2-4 and 4-6. All model residuals were checked for normality with QQ plots, and no data transformation was necessary for the lme-analysis. The analyses were performed in R (R Core Team 2013) with the function lme (package NLME; Pinheiro et al., 2011). For each analysis, a model selection was made and only the results of the model yielding the lowest AIC value are presented.

Using Jaccard distance matrices (Legendre \& Legendre, 1998), the differences in protist community composition due to the temperature treatments were determined. This analysis was carried out to determine the difference in protist community composition among each of the four sites and for early and late succession at days 2, 4, and 6. For this calculation, the program PRIMER (Primer 6, Version 6.1.6, Primer E-Ltd., Clarke \& Gorley, 2006) was used. Community structure was visualized with NMDS plots. We used two dimensions as the stress values were always smaller than 0.2 . We also conducted multivariate dispersion (MVDISP) analysis and analysis of similarity (ANOSIM) for these treatments. MVDISP provides an estimate of the dispersion among replicates within each community. This value is obtained by computing an Index of Multivariate Dispersion (IMD), in which negative values indicate lower dispersion of groups with high temperature variation compared with the groups with normal temperature variation. For the ANOSIM analysis, the output is a global $R$ value, which is used to measure the compositional distance between groups of high- and normal-temperature variation. Communities are considered significantly different when $R>0.5$.

\section{Results}

\section{Lowest trophic level - bacteria}

For the lowest trophic level, temperature variation had a strong effect on bacterial density when this density was considered in its interaction with sampling day $(P$ value $<0.001$, Fig. $1 \mathrm{a}$, b; see Table S1 for full results), but was not significant as a main effect over the whole course of the experiment (Fig. 1c; $P$-value $=0.91$ ). While on Day 2 there were more bacteria in the high-variation treatment than in the normal-variation treatment, this difference decreased for days 4 and 6, indicating a stronger decline through time when the bacteria were exposed to higher variation. Irrespective of temperature variation, the bacteria of early successional communities had a higher density than late successional bacteria (Fig. 1c; $P$-value $<0.001$ ); this difference was weaker on the last sampling day (Fig. S3), which resulted in a significant interaction with sampling day $(P$-value $=0.002)$.

\section{Intermediate trophic level - protists}

The effect of temperature variation on community structure was evaluated firstly on alpha-diversity, secondly on its effect on species composition through time (temporal beta-diversity) for each community, and thirdly on species composition between the treatments at the three sampling days.

The temperature treatments changed the number of protist species, and thus alpha-diversity over time, when all days except the initial start day (Day 0) were considered (interaction of temp var. with days; $P$-value 0.045; Fig. 2; Table S3). On Day 2 and Day 4, there were fewer species present in the high temperature variation 

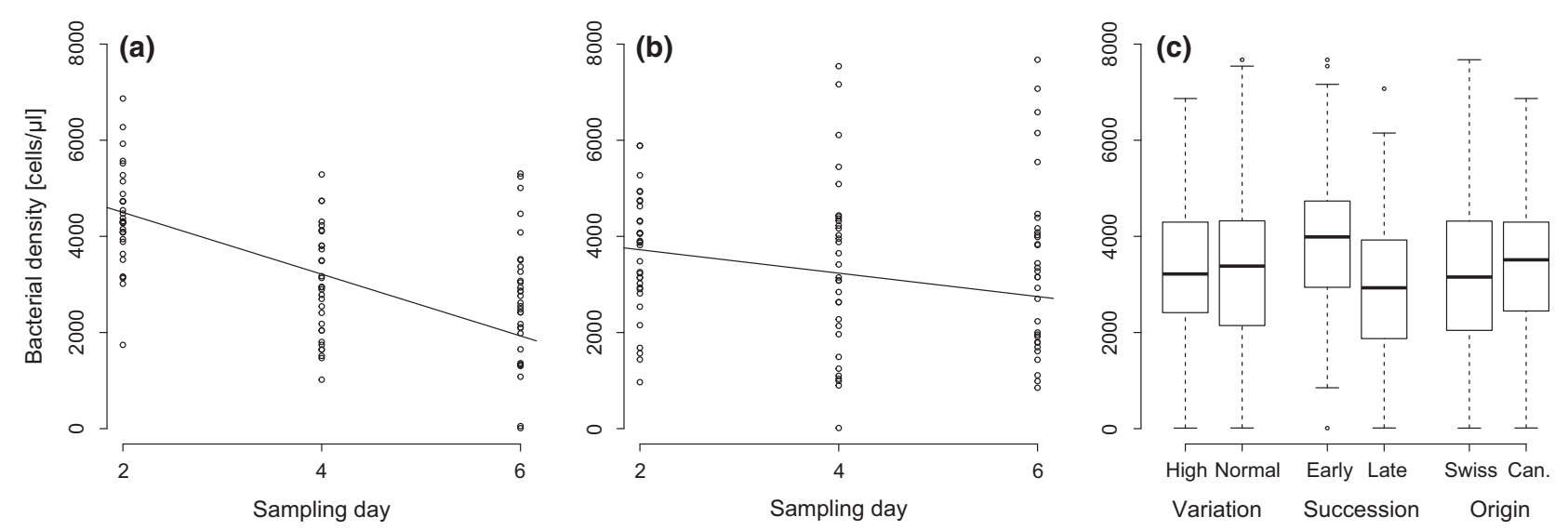

Fig. 1 Effect of temperature variation over time on bacterial density [cells per $\mu$ l] in (a) high-variation and (b) normal-variation treatments. The regression lines in (a) and (b) are from univariate analyses. Note that initial bacterial density on Day 0 was 1000 cells $\mu 1^{-1}$ for both temperature treatments. Overall effects of temperature variation, succession, and origin are shown as box-plots in (c): only succession has a statistically significant main effect; origin was never significant; temperature variation was significant through its interaction with sampling day (see panels a and b). See Table S1 for full results and Fig. S3 for additional graphs.

treatment than the normal temperature variation treatment. However, this effect disappeared by the end of the experiment (Day 6). When only the factor 'temperature variation' was considered, this difference in alphadiversity between the high- and the normal-variation treatment became even more significant ( $P$ value $=0.012$; Table S3). Note also that late successional and Canadian communities were more species rich from the outset (see Fig. S4 and Table S3). Finally, the number of protist morphospecies was positively related to bacterial density $(P$-value $=0.021$; Fig. S5).

The change in protist species beta-diversity through time was affected by temperature variation (Fig. 3a; $P$ value $=0.001$ ) and community origin (Fig. $3 b ; P$ value $=0.038)$, but was independent of successional stage. Interestingly, the Swiss communities changed more over time and were more affected by high temperature variations than the Canadian ones, resulting in a significant interaction between both factors (Fig. 3c; $P$-value $=0.042$; see Table S4 for full results).

The high temperature variation treatment significantly affected protist community composition at each sampling day; however, the effects depended on the successional stage of the community. No trend was visible for early successional communities (Fig. 4a). For the late successional communities, the R-values, which measure the differences between community composition in high- and normal-temperature variation, tended to increase over time (Fig. 4b). This increase in R-values through time means that the community composition in the high-variation treatment became increasingly different over the time course of the experiment when compared with the community composition in the normal-variation treatment (see also Fig. S6).

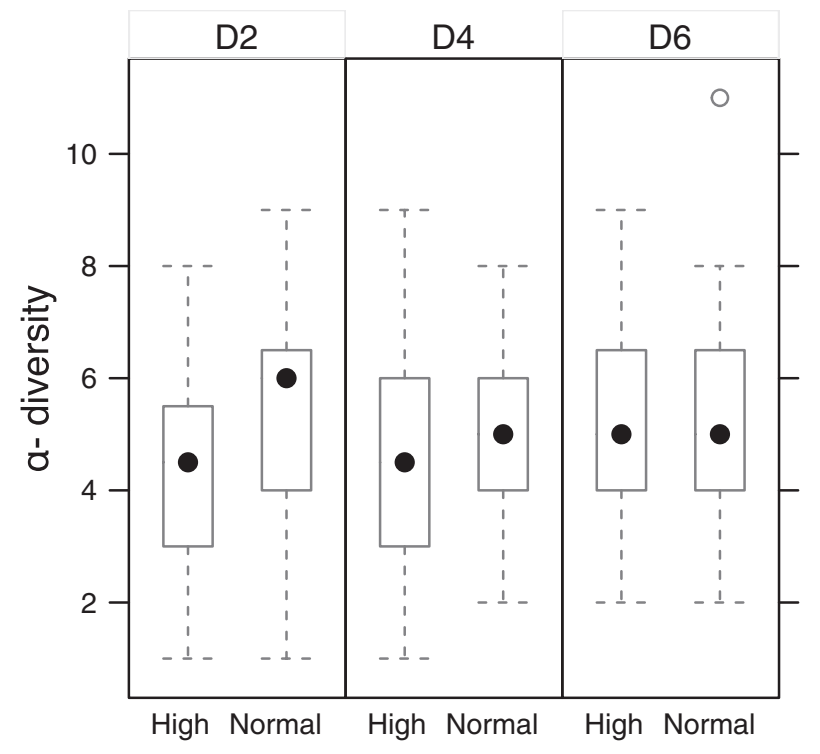

Fig. 2 Protist species numbers (alpha-diversity) on the three sampling days (D2 to D6) as a function of temperature variation (high and normal), in which the main effect was statistically significant (data from all days combined; $P$-value $=0.01$ ), as well as its interaction with sampling day $(P$-value $=0.04)$; see Table S3 for full results. The effect is very strong on Day 2 but decreased over time to finally vanish on Day 6 .

The changes in protist species composition between the treatments on the three sampling days were mostly due to several species that drastically changed their relative abundance. The morphospecies cf. Euplotes sp. (Msp. 9) and Msp 11 (Tetrahymena cf. pyriformis) as well as Chlamydomonas sp. (Msp. 23) and Msp. 37 (unknown flagellate sp. D) were no longer detectable in the highvariation treatments, while they stayed abundant in the normal-variation treatment (see Table S6 and Fig. S7). 
(a)

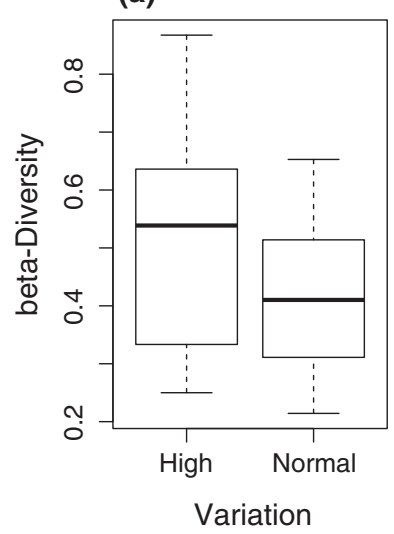

(b)

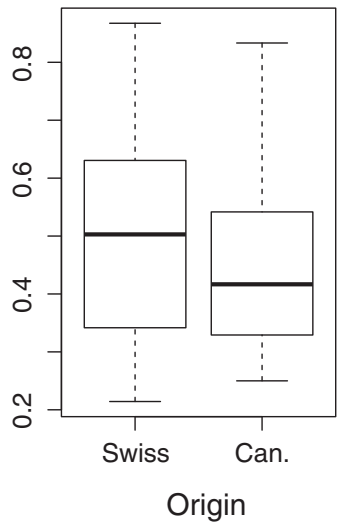

(c)

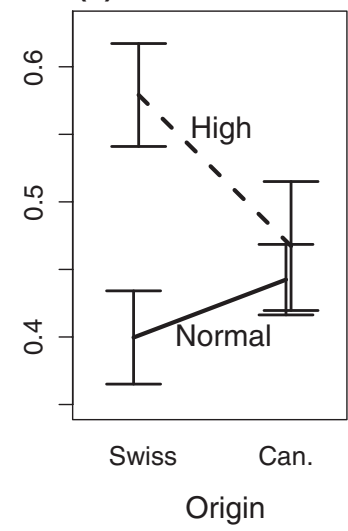

Fig. 3 Effects on temporal protist beta-diversity for (a) temperature variation (box plot), (b) community origin (box plot; Can. = Canada), and (c) both factors (interaction plot of variation and origin). Beta-diversity changes significantly more in high-variation compared with normal-variation treatments (a), as well as in Swiss compared with Canadian treatments (b). Swiss communities exposed to high-variation treatments changed much more than the control communities exposed to normal-variation, while Canadian communities changed in a similar way in high and normal treatments. See Table S4 for full results.
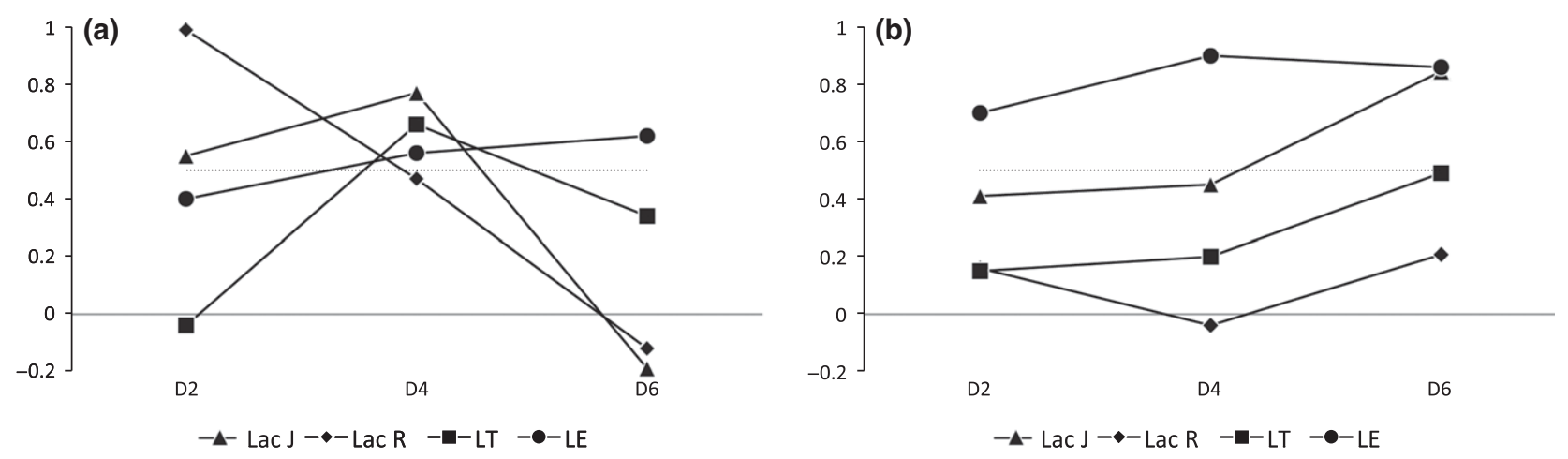

Fig. 4 R-values of the pair-wise tests between high- and normal-variation treatments for the three sampling days (D2 to D6). R-values describe divergence in composition due to temperature variation and are considered significant when higher than 0.5 (dotted line). (a) Early successional communities; (b) late successional communities. Legend: Lac J, Lac des Joncs; Lac R, Lac Rimouski; LT, Les Tenasses; LE, Les Embreux.

Two other morphospecies also suffered severely from high temperature variation but were not pushed near to extinction. The Msp. 10 (heterotrophic-nano-flagellate (HNF) sp. B) and 18 (Chrysomonadina sp. D) lost 16 and 9 percentage points of relative occurrence, respectively, compared to their occurrence in the normal temperature variation treatment. All other morphospecies either did not change or slightly gained in relative occurrence throughout the time course of the experiment, independent of temperature treatment (see Table S6 and Fig. S7).

\section{Mosquito mortality}

We used Poisson-family glm to relate the number of dead mosquitoes to the three factors of the study. Neither temperature variation, successional stage, nor community origin had a significant effect on mosquito mortality (see Table S5 for detailed results).

\section{Community respiration}

The results of community respiration at Day 6 showed that high temperature variation negatively affected this global measure of ecosystem functioning (Fig. 5, Table S2 for details on the results). Communities that experienced the normal temperature variation treatment respired significantly more than communities in the high temperature variation treatment $(P$-value $<0.001$; Fig. 5$)$. These results could appear consistent with the bacterial densities, in which more bacteria were present in normal temperature variation than in high temperature variation on Day 6 (Fig. 1a, b). However, we found no relationship between respiration and bacterial density in our 


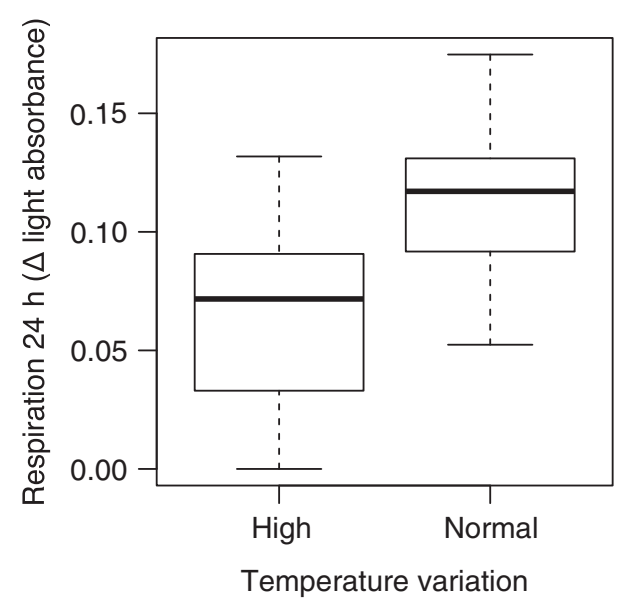

Fig. 5 Effects of temperature variation on productivity. Communities in the normal-variation environment respired more than the ones in the high-variation environment. The respiration measurements were conducted on Day 6. See Table S2 for full results.

experiment (linear model, $P$-value $=0.29$ ). Globally, early successional communities are more productive $(P$-value $=0.002 ;$ Fig. S8), but there was no difference in respiration between the early communities of different origins; however, late successional communities from Switzerland were less productive than late successional communities from Canada, irrespective of temperature variation, resulting in a significant interaction of the factors succession and origin $(P$-value $=0.018$; Fig. S8, Table 22 for full details on results).

\section{Discussion}

Increased temperature variation affected food web dynamics and community respiration differently than was hypothesized. The successional stage of the communities only played a significant role in altering the effect of temperature variation for the intermediate trophic level. Interestingly, although there were some significant differences in the food webs from Canada and Switzerland, the impact of increased temperature variation was similar in all food webs, irrespective of origin. The only exception was for protist beta-diversity. These results highlight that predicting the effects of global change on community dynamics will be challenging, and more work is necessary to tease apart the various effects of temperature increase and temperature variation among and within trophic levels.

For the bottom trophic level, we found that the bacteria initially had a higher density in the increased temperature variation treatment than in normal temperature variation, as was hypothesized. However, after this initial boost in growth (Day 0-Day 2), the bacteria decreased their density markedly and reached smaller densities than the bacteria in normal temperature variation by the end of the experiment (see Fig. 1a, b). This indicates a faster response due to higher usable energy input in the high temperature variation treatment, with bacteria growing faster until their 'carrying capacity' is reached, but then severely declining - a result consistent with other studies (e.g. Ratkowsky et al., 1982, 1983; Iyer-Biswas et al., 2014). This decline is likely due to the combined effects of stronger predation by protists and increased inter- and intraspecific competition.

We observed a general positive relationship between bacterial density and the number of protist species. This relationship is expected because higher density of prey leads to higher protist densities and thus higher detectability of rare protist species. However, we observe a lower alpha-diversity of protists in the high temperature variation treatment, indicating that the potential benefit of higher bacterial densities was offset by the detrimental effect of temperature variation on the nontolerant protist morphospecies. Accordingly, we found that four morphospecies severely declined in the high temperature variation treatment. These results suggest that the ability of species to persist depends on their range of thermal tolerance. However, the difference in alpha-diversity between the two temperature treatments became weaker over time, suggesting an adaptation of some species.

The change in protist composition through time (betadiversity) was greater in the high temperature variation treatment, and also in the Swiss origin. Furthermore, the interaction of both factors is significant (see Fig. 3c). One reason for this pattern is that protist diversity in the Swiss sites is typically lower than in the Canadian sites (see also Zander et al., 2016), which may render communities more susceptible to environmental changes. Another reason could be that Swiss protists are less adapted to the Sarracenia pitcher habitat because they have shared a shorter evolutionary history with the plant than the protist species associated with the plant in North America. However, as hypothesized, species composition in early successional communities was less affected by high temperature variation than late successional communities, for which we observed increasing divergence in composition with time (Fig. 4). The environmental filtering that occurs with higher temperature variation thus appears to be stronger for these late stage communities, which are typically composed of larger and more competitive species, while the early successional communities harbour more pioneer species (e.g. lakes: Sommer et al., 1986; S. purpurea system: Gray, 2012; Miller \& terHorst, 2012; Zander et al., 2016).

Contrary to our hypothesis, we did not observe a significant change in mosquito mortality in the high 
temperature variation treatment. Our argument was based on the allometric relationship where body size is larger in higher trophic levels (Woodward et al., 2005) and was supported in experimental studies (e.g. Petchey et al., 1999). In our case, the absence of an effect may be due to the fact that Wyeomyia larvae regularly experience high temperature variation inside the pitchers of S. purpurea, and that our experimental thermal range never transgressed the physiological limits of the species. Note that Wyeomyia larvae are strictly endemic to pitchers and have co-evolved with S. purpurea since the Wisconsin glaciation (Istock \& Weisburg, 1987; Hard et al., 1993).

Community respiration, which was measured at the end of the experiment, significantly decreased with high temperature variation. We hypothesized that increased variation would not affect respiration, because higher respiration rates in temperatures towards an optimum would be compensated by lower rates in extreme temperatures. Interestingly, we found no significant relationship between respiration and bacterial density in our experiment, which could be explained by the reported negative relationship between metabolic rate and density (DeLong et al., 2014). Consequently, our result suggests a density-independent negative effect of temperature variability on metabolism and indicates that, in the long run, ecosystem functioning will be negatively affected by increased variability. This result may be general, as high temperature variation is forcing organisms to spend more time in physiologically stressful conditions.

Studies on temperature variability are important as they explore the effects of a relatively poorly studied component of climate change research, especially at the community and food web levels. The S. purpurea system provides an excellent first step in answering this essential research question. This system is small enough to be kept in incubators and has been widely used experimentally due to the short generation time of the species, its replicability, and its wide distribution across North America and western Europe (e.g. Kneitel \& Miller, 2002, 2003; Miller et al., 2002; Gebühr et al., 2006; Gray et al., 2006; Buckley et al., 2010; Baiser et al., 2012; Krieger \& Kourtev, 2012). The inquiline communities are composed of naturally co-occurring species (with the exception of Wyeomyia in the Swiss communities) and exist for nearly two years before their leaves die, which is much longer than ephemeral systems. We thus expect our results to be more relevant to largescale freshwater systems than if randomly assembled systems were used.

However, this system also has its limitations. Notably, because different taxa with highly variable densities and generation time are found across the different trophic levels, it was difficult to assess the effects of treatments with the same methodology for all levels. In our case, we concentrated on global densities for bacteria, on community composition for protists, on mortality rates for the mosquitoes, and on respiration as a global ecosystem functioning measurement of the whole system. For the mosquitoes, we could only use mortality as a readout because the generation time was too long to allow the inclusion of population growth/ decline in our study. Also, this measurement would be technically challenging for any species that does not complete its life cycle inside the boundaries of an aquatic system. These decisions allowed for the experiment to be conducted with a large number of treatments, but limited our ability to test hypotheses that are designed for the whole food web and to have a high level of replication. Note that, because species in higher trophic levels are typically larger and have a longer generation time, any research on food web structure and dynamics will face similar difficulties. A second limitation is that this system lacks the complexity of larger aquatic systems, as it mainly contains species with very fast generation times and nonsexual life cycles. These fast life cycles, especially of the bacteria and protist in this system, allowed the species to quickly respond, and possibly to adapt, to temperature perturbations. Therefore, it will be difficult to generalize our results to larger species of higher taxonomic orders because, when considering the adaptability of species, the interaction between generation time and the amount and speed of temperature-variability change is pivotal. It is important to stress, however, that the short generation time of the species in the Sarracenia system makes the results from this six day experiment 'equivalent' to results of higher order species after they have undergone 5-40 generations or more (depending on the trophic level).

The effect of temperature variation has been tackled experimentally in several studies (Descamps-Julien \& Gonzalez, 2005; Jiang \& Morin, 2007; Shurin et al., 2010; Burgmer \& Hillebrand, 2011; Tuck \& Romanuk, 2012) and in general, was found to be beneficial, notably for the coexistence of two competing protist species (Jiang \& Morin, 2007). These results can be interpreted within the concept of the intermediate disturbance hypothesis, where moderate variability will be generally beneficial to the community by increasing the range of environmental conditions, allowing more species to persist. This result led Burgmer \& Hillebrand (2011) to hypothesize that higher temperature variation should foster species coexistence in a species-rich phytoplankton system. Contrary to their hypothesis, they found the opposite, which is in line with our results. This finding highlights the sensitivity of the responses to the range in temperature variation. Here, we set our experiment 
to match extreme variation measured in our natural system $\left(4-35^{\circ} \mathrm{C}\right.$ in one week, with $27^{\circ} \mathrm{C}$ daily variation; Figs S2, S10-S12; Table S7, see also Bradshaw, 1980). Our result thus shows that current levels of variation do lead these natural systems beyond the positive effect phase of increased temperature variation, contrary to the above studies. It is likely that the predicted increase in climatic extreme events will put natural communities like the one studied here in an even greater threat of disruption.

Globally, our results highlight that the effects of increased temperature variability can be different across trophic levels. This variability is in part attributable to experimental constraints imposed by the varying life cycles, particularly the generation time, of the species in a food web. Moreover, building a general theory regarding the effects of high temperature variability at the food web level remains challenging. This theory could be possible if the thermal limits of species would change predictably with body size, as the latter is known to increase with trophic levels (e.g. Cohen et al., 2003). However, data about such a relationship are scant and do not reveal any clear pattern (Stevenson, 1985; Liu et al., 1995; Stewart et al., 2013). The effects of temperature variability at the community level may then be idiosyncratic. Future research should concentrate on obtaining more information about thermal ranges for species spanning a wide range of body size in various taxonomic groups. Such data are a prerequisite for the formulation of mechanistic models for natural large-scale communities, going beyond the scope of small-system experiments, like in the present one and in others (e.g. Tuck \& Romanuk, 2012; Sentis et al., 2014). Mitigating the effects of global changes can only be achieved by a consideration of the effects of increased average temperature and thermal variability.

\section{Acknowledgements}

We would like to warmly thank Dominique Gravel for the use of his laboratory at the University of Québec in Rimouski. We also thank Steve Vissault, Renaud McKinnon, Timothée Poisot, Génika Hulliger, Marie-Amélie Girardet, and Elodie Parain for aiding in marking leaves, collecting samples, and in laboratory preparation. Funding sources for this project are the Swiss National Science Foundation (SNSF) Grant awarded to LFB (31003A_138489) and the SNSF International Short Visit Grant awarded to SMG.

\section{Author contributions}

All authors designed the research; AZ and SMG conducted the research; AZ, LFB, and SMG wrote the manuscript; all authors edited the manuscript. LFB and SMG funded the project.

\section{References}

Adlassnig W, Mayer E, Peroutka M, Pois W, Lichtscheidl IK (2010) Two American Sarracenia species as neophyta in central Europe. Phyton (Horn), 49, 279-292.

Altermatt F, Fronhofer EA, Garnier A et al. (2015) Big answers from small worlds: a user's guide for protist microcosms as a model system in ecology and evolution. Methods in Ecology and Evolution, 6, 218-231.

Baiser B, Gotelli NJ, Buckley HL, Miller TE, Ellison AM (2012) Geographic variation in network structure of a nearctic aquatic food web. Global Ecology and Biogeography, 21, 579-591.

Bazzaz FA (1979) The physiological ecology of plant succession. Annual Review of Ecology and Systematics, 10, 351-371.

Beisner BE, McCauley E, Wrona FJ (1997) The influence of temperature and food chain length on plankton predator-prey dynamics. Canadian Journal of Fisheries and Aquatic Sciences, 54, 586-595.

Bozinovic F, Bastías DA, Boher F, Clavijo-Baquet S, Estay Sergio A, Jr MJA (2011) The mean and variance of environmental temperature interact to determine physiological tolerance and fitness. Physiological and Biochemical Zoology, 84, 543-552.

Bradshaw W (1980) Thermoperiodism and the thermal environment of the pitcherplant mosquito, Wyeomyia smithii. Oecologia, 46, 13-17.

Brown JH, Gillooly JF, Allen AP, Savage VM, West GB (2004) Toward a metabolic theory of ecology. Ecology, 85, 1771-1789.

Buckley HL, Miller TE, Ellison AM, Gotelli NJ (2003) Reverse latitudinal trends in species richness of pitcher-plant food webs. Ecology Letters, 6, 825-829.

Buckley HL, Miller TE, Ellison AM, Gotelli NJ (2010) Local- to continental-scale variation in the richness and composition of an aquatic food web. Global Ecology and Biogeography, 19, 711-723.

Burgmer T, Hillebrand H (2011) Temperature mean and variance alter phytoplankton biomass and biodiversity in a long-term microcosm experiment. Oikos, 120, 922-933.

Carmen C (2007) MicroResp Technical Manual - A Versatile Soil Respiration System. Macaulay Institute, Aberdeen.

Clarke KR, Gorley RN (2006) PRIMER v6: User Manual/Tutorial. Primer-E, Plymouth.

Cochran-Stafira DL, von Ende CN (1998) Integrating bacteria into food webs: studies with Sarracenia purpurea inquilines. Ecology, 79, 880-898.

Cohen JE, Jonsson T, Carpenter SR (2003) Ecological community description using the food web, species abundance, and body size. Proceedings of the National Academy of Sciences, 100, 1781-1786.

Daufresne M, Lengfellner K, Sommer U (2009) Global warming benefits the small in aquatic ecosystems. Proceedings of the National Academy of Sciences, 106, 12788-12793.

DeLong JP, Hanley TC, Vasseur DA (2014) Competition and the density dependence of metabolic rates. Journal of Animal Ecology, 83, 51-58.

Descamps-Julien B, Gonzalez A (2005) Stable coexistence in a fluctuating environment: an experimental demonstration. Ecology, 86, 2815-2824.

Deutsch CA, Tewksbury JJ, Huey RB, Sheldon KS, Ghalambor CK, Haak DC, Martin PR (2008) Impacts of climate warming on terrestrial ectotherms across latitude. Proceedings of the National Academy of Sciences, 105, 6668-6672.

Elliott JA, Jones ID, Thackeray SJ (2006) Testing the sensitivity of phytoplankton communities to changes in water temperature and nutrient load, in a temperate lake. Hydrobiologia, 559, 401-411.

Foster B, Tilman D (2000) Dynamic and static views of succession: testing the descriptive power of the chronosequence approach. Plant Ecology, 146, 1-10.

Fragnière Y (2012) Colonisation of Sarracenia purpurea pitchers in Swiss populations. Master Thesis, Unit of Ecology \& Evolution, University of Fribourg, Switzerland.

Gebühr C, Pohlon E, Schmidt AR, Küsel K (2006) Development of microalgae communities in the Phytotelmata of Allochthonous populations of Sarracenia purpurea (Sarraceniaceae). Plant Biology (Stuttgart), 8, 849-860.

Gilman SE, Urban MC, Tewksbury J, Gilchrist GW, Holt RD (2010) A framework for community interactions under climate change. Trends in Ecology and Evolution, 25, $325-331$

Gray S (2012) Succession in the aquatic Sarracenia purpurea community: deterministic or driven by contingency? Aquatic Ecology, 46, 487-499.

Gray S, Miller T, Mouquet N, Daufresne T (2006) Nutrient limitation in detritus-based microcosms in Sarracenia purpurea. Hydrobiologia, 573, 173-181.

Gray SM, Dykhuizen DE, Padilla DK (2015) The effects of species properties and community context on establishment success. Oikos, 124, 355-363.

Gutschick VP, BassiriRad H (2003) Extreme events as shaping physiology, ecology, and evolution of plants: toward a unified definition and evaluation of their consequences. New Phytologist, 160, 21-42.

Hard JJ, Bradshaw WE, Holzapfel CM (1993) The genetic basis of photoperiodism and its evolutionary divergence among populations of the pitcher-plant mosquito, Wyeomyia smithii. American Naturalist, 142, 457-473. 
Heard SB (1998) Capture rates of invertebrate prey by the pitcher plant, Sarracenia purpurea L. The American Midland Naturalist, 139, 79-89.

Hoekman D (2007) Top-down and bottom-up regulation in a detritus-based aquatic food web: a repeated field experiment using the pitcher plant (Sarracenia Purpurea) inquiline community. The American Midland Naturalist, 157, 52-62.

terHorst CP, Miller TE, Levitan DR (2010) Evolution of prey in ecological time reduces the effect size of predators in experimental microcosms. Ecology, 91, 629-636.

IPCC (2013) Climate Change 2013: The Physical Science Basis. In: Contribution of Working Group I to the Fifth Assessment Report of the Intergovernmental Panel on Climate Change (eds Stocker TF, Qin D, Plattner G-K, Tignor M, Allen SK, Boschung J, Nauels A, Xia Y, Bex V, Midgley PM). Cambridge University Press, Cambridge, UK

Istock CA, Weisburg WG (1987) Strong habitat selection and the development of population structure in a mosquito. Evolutionary Ecology, 1, 348-362.

Iyer-Biswas S, Wright CS, Henry JT et al. (2014) Scaling laws governing stochastic growth and division of single bacterial cells. Proceedings of the National Academy of Sciences of the United States of America, 111, 15912-15917.

Jiang L, Morin PJ (2007) Temperature fluctuation facilitates coexistence of competing species in experimental microbial communities. Journal of Animal Ecology, 76, 660668

Jiang L, Joshi H, Flakes SK, Jung Y (2011) Alternative community compositional and dynamical states: the dual consequences of assembly history. Journal of Animal Ecology, 80, 577-585.

Kadowaki K, Inouye BD, Miller TE (2012) Assembly-history dynamics of a pitcherplant protozoan community in experimental microcosms. PLoS ONE, 7, e42651.

Kneitel JM, Miller TE (2002) Resource and top-predator regulation in the pitcher plant (Sarracenia purpurea) inquiline community. Ecology, 83, 680-688.

Kneitel JM, Miller TE (2003) Dispersal rates affect species composition in metacommunities of Sarracenia purpurea inquilines. American Naturalist, 162, 165-171.

Krieger JR, Kourtev PS (2012) Bacterial diversity in three distinct sub-habitats within the pitchers of the northern pitcher plant, Sarracenia purpurea. FEMS Microbiology Ecology, 79, 555-567.

Laurance WF, Carolina Useche D, Shoo LP et al. (2011) Global warming, elevational ranges and the vulnerability of tropical biota. Biological Conservation, 144, 548-557.

Legendre P, Legendre L (1998) Numerical Ecology (2nd English edn). Elsevier, Amsterdam.

Lindner M, Maroschek M, Netherer S et al. (2010) Climate change impacts, adaptive capacity, and vulnerability of European forest ecosystems. Adaptation of Forests and Forest Management to Changing Climate Selected papers from the conference on 'Adaptation of Forests and Forest Management to Changing Climate with Emphasis on Forest Health: A Review of Science, Policies and Practices', Umeå, Sweden, August 25-28, 2008, 259, 698-709.

Liu S-S, Zhang G-M, Zhu J (1995) Influence of temperature variations on rate of development in insects: analysis of case studies from entomological literature. Annals of the Entomological Society of America, 88, 107-119.

Lloyd J, Taylor JA (1994) On the temperature dependence of soil respiration. Functional Ecology, 8, 315-323.

Lortie CI, Brooker RW, Choler P, Kikvidze Z, Michalet R, Pugnaire FI, Callaway RM (2004) Rethinking plant community theory. Oikos, 107, 433-438.

Maracchi G, Sirotenko O, Bindi M (2005) Impacts of present and future climate variability on agriculture and forestry in the temperate regions: Europe. Climatic Change, 70, 117-135.

Miller T, terHorst C (2012) Testing successional hypotheses of stability, heterogeneity, and diversity in pitcher-plant inquiline communities. Oecologia, 170, 243-251.

Miller TE, Kneitel JM, Burns JH (2002) Effect of community structure on invasion success and rate. Ecology, 83, 898-905.

Moore M, Folt C, Stemberger R (1996) Consequences of elevated temperatures for zooplankton assemblages in temperate lakes. Archiv für Hydrobiologie, 135, 289-319.

del Moral R, Wood DM (1993) Early primary succession on the volcano Mount St. Helens. Journal of Vegetation Science, 4, 223-234.

Nakazawa T, Doi H (2012) A perspective on match/mismatch of phenology in community contexts. Oikos, 121, 489-495.

Nastase AJ, Rosa CDL, Newell SJ (1995) Abundance of Pitcher-Plant Mosquitoes, Wyeomyia smithii (Coq.) (Diptera: Culicidae) and Midges, Metriocnemus knabi Coq. (Diptera: Chironomidae), in Relation to Pitcher Characteristics of Sarracenia purpurea L. American Midland Naturalist, 133, 44-51.

Neuheimer AB, Taggart CT (2007) The growing degree-day and fish size-at-age: the overlooked metric. Canadian Journal of Fisheries and Aquatic Sciences, 64, 375-385.

Nguyen KDT, Morley SA, Lai C-H, Clark MS, Tan KS, Bates AE, Peck LS (2011) Upper temperature limits of tropical marine ectotherms: global warming implications. PLOS ONE, 6, e29340.
Odum EP (1969) The strategy of ecosystem development. Science, 164, 262-270.

O'Gorman EJ, Benstead JP, Cross WF et al. (2014) Climate change and geothermal ecosystems: natural laboratories, sentinel systems, and future refugia. Global Change Biology, 20, 3291-3299.

Parmesan C (2006) Ecological and evolutionary responses to recent climate change. Annual Review of Ecology, Evolution, and Systematics, 37, 637-669.

Petchey OL, McPhearson PT, Casey TM, Morin PJ (1999) Environmental warming alters food-web structure and ecosystem function. Nature, 402, 69-72.

Pineda-garcía F, Paz H, Meinzer FC (2013) Drought resistance in early and late secondary successional species from a tropical dry forest: the interplay between xylem resistance to embolism, sapwood water storage and leaf shedding. Plant, Cell and Environment, 36, 405-418.

Pinheiro J, Bates D, DebRoy SS, Sarkar D, the R Development Core Team (2011). nlme: Linear and Nonlinear Mixed Effects Models. R package version:3.1-103.

R Core Team (2013) R: A language and environment for statistical computing. Version 3.0.0. R Foundation for Statistical Computing, Vienna, Austria.

Ratkowsky DA, Olley J, McMeekin TA, Ball A (1982) Relationship between temperature and growth rate of bacterial cultures. Journal of Bacteriology, 149, 1-5.

Ratkowsky DA, Lowry RK, McMeekin TA, Stokes AN, Chandler RE (1983) Model for bacterial culture growth rate throughout the entire biokinetic temperature range Journal of Bacteriology, 154, 1222-1226.

Salerno F, Gambelli S, Viviano G et al. (2014) High alpine ponds shift upwards as average temperatures increase: a case study of the Ortles-Cevedale mountain group (Southern Alps, Italy) over the last 50 years. Global and Planetary Change, 120, 81-91.

Sentis A, Hemptinne J, Brodeur J (2014) Towards a mechanistic understanding of temperature and enrichment effects on species interaction strength, omnivory and food web structure. Ecology Letters, 17, 785-793.

Shurin JB, Winder M, Adrian R et al. (2010) Environmental stability and lake zooplankton diversity - contrasting effects of chemical and thermal variability. Ecology Letters, 13, $453-463$.

Sommer U, Gliwicz ZM, Lampert W, Duncan A (1986) The PEG-model of seasonal succession of planktonic events in fresh waters. Archiv fur Hydrobiologie, 106, $433-471$

Stevenson R (1985) The relative importance of behavioral and physiological adjustments controlling body temperature in terrestrial ectotherms. American Naturalist, 126, 362-386.

Stewart BA, Close PG, Cook PA, Davies PM (2013) Upper thermal tolerances of key taxonomic groups of stream invertebrates. Hydrobiologia, 718, 131-140.

Streble H, Krauter D (2002) Das Leben im Wassertropfen: Mikroflora und Mikrofauna des Süßwassers(9th edn). Kosmos (Franckh-Kosmos), Stuttgart.

Strecker AL, Cobb TP, Vinebrooke RD (2004) Effects of experimental greenhouse warming on phytoplankton and zooplankton communities in fishless alpine ponds. Limnology and Oceanography, 49, 1182-1190.

Thompson RM, Beardall J, Beringer J, Grace M, Sardina P (2013) Means and extremes: building variability into community-level climate change experiments. Ecology Letters, 16, 799-806

Traill LW, Lim MLM, Sodhi NS, Bradshaw CJA (2010) Mechanisms driving change: altered species interactions and ecosystem function through global warming. Journal of Animal Ecology, 79, 937-947.

Tuck C, Romanuk TN (2012) Robustness to thermal variability differs along a latitudinal gradient in zooplankton communities. Global Change Biology, 18, 1597-1608.

Vasseur DA, DeLong JP, Gilbert B et al. (2014) Increased temperature variation poses greater risk to species than climate warming. Proceedings of the Royal Society of London B: Biological Sciences, 281, 20132612.

Walther G-R, Post E, Convey P et al. (2002) Ecological responses to recent climate change. Nature, 416, 389-395.

Woodward G, Hildrew AG (2002) Food web structure in riverine landscapes. Freshwater Biology, 47, 777-798.

Woodward G, Ebenman B, Emmerson M, Montoya JM, Olesen JM, Valido A, Warren PH (2005) Body size in ecological networks. Trends in Ecology and Evolution, 20, $402-409$.

Wootton JT (1993) Size-dependent competition: effects on the dynamics vs. the end point of mussel bed succession. Ecology, 74, 195-206.

Yvon-Durocher G, Caffrey JM, Cescatti A et al. (2012) Reconciling the temperature dependence of respiration across timescales and ecosystem types. Nature, 487, 472-476.

Zander A, Gravel D, Bersier L-F, Gray SM (2016) Top predators affect the composition of naive protist communities, but only in their early-successional stage Oecologia, 180, 519-528 


\section{Supporting Information}

Additional Supporting Information may be found in the online version of this article:

Appendix S1 Supplementary figures and tables.

Figure S1 Worldclim data for the four sites used in the experiment.

Figure S2 Temperature treatments of the experiment and measured temperature variation in a leaf of S. purpurea in July 2012.

Figure S3 Bacterial Density; early and late succession.

Figure S4 Protist $\alpha$-diversity in the European and North American S. purpurea communities.

Figure S5 Scatter plot of number of protist species against bacterial density.

Figure S6 NMDS plots of all sites.

Figure S7 Effect of temperature variation on protist species occurrence.

Figure S8 Effects of succession and origin on community respiration.

Figure S9 Daily maxima temperatures at the LT site for the month of June, July and August 2012.

Figure S10 Temperature history of June and July 2012 at the LT site.

Figure S11 Influence of light intensity on temperature difference between inside the pitchers and the bog water.

Figure S12 Measured temperature variation in one leaf of S. purpurea during June 2012 in Les Tenasses (LT).

Table S1 Results from the generalized linear model for bacterial density.

Table S2 Results from the linear model for respiration.

Table S3 Results from the generalized linear model for protist $\alpha$-diversity.

Table S4 Results from the linear model for beta-diversity.

Table S5 Results from the generalized linear model with Poisson regression for mosquito mortality.

Table S6 Relative occurrence of protist morpho-species.

Table S7 Temperature and light intensity measurements at the Les Tenasses site. 